\title{
The Anti-Fasciolasis Properties of Silver Nanoparticles Produced by Trichoderma harzianum and Their Improvement of the Anti-Fasciolasis Drug Triclabendazole
}

\author{
Youssuf A. Gherbawy ${ }^{1,2, *}$, Ismail M. Shalaby ${ }^{1}$, Mahmoud Syed Abd El-sadek ${ }^{3}$, \\ Hesham M. Elhariry ${ }^{1,4}$ and AbdelElah A. Banaja ${ }^{1}$
}

1 Department of Biological Sciences, Faculty of Science, Taif University, P.O. Box 888, Taif 21974, Saudi Arabia; E-Mails: ismail.mehrez@gmail.com (I.M.S.); hesham_elhariry@yahoo.com (H.M.E.); aabanaja@yahoo.com (B.A.A.) Botany Department, Faculty of Science, South Valley University, Qena 83523, Egypt

3 Nanomaterial Lab., Physics Department, Faculty of Science, South Valley University, Qena 83523, Egypt; E-Mail: mahmoud.abdelsadek@sci.svu.edu.eg

4 Department of Food Science, Faculty of Agriculture, Ain Shams University, POB 68- Hadayek Shoubra, Cairo 11241, Egypt

* Author to whom correspondence should be addressed; E-Mail: youssufgherbawy@yahoo.com; Tel.: +966-55-3993-906.

Received: 22 September 2013; in revised form: 21 October 2013 / Accepted: 28 October 2013 / Published: 5 November 2013

\begin{abstract}
Recently, new strains of Fasciola demonstrated drug resistance, which increased the need for new drugs or improvement of the present drugs. Nanotechnology is expected to open some new opportunities to fight and prevent diseases using an atomic scale tailoring of materials. The ability to uncover the structure and function of biosystems at the nanoscale, stimulates research leading to improvement in biology, biotechnology, medicine and healthcare. The size of nanomaterials is similar to that of most biological molecules and structures; therefore, nanomaterials can be useful for both in vivo and in vitro biomedical research and applications. Therefore, this work aimed to isolate fungal strains from Taif soil samples, which have the ability to synthesize silver nanoparticles. The fungus Trichoderma harzianum, when challenged with silver nitrate solution, accumulated silver nanoparticles (AgNBs) on the surface of its cell wall in $72 \mathrm{~h}$. These nanoparticles, dislodged by ultrasonication, showed an absorption peak at $420 \mathrm{~nm}$ in a UV-visible spectrum, corresponding to the plasmon resonance of silver nanoparticles. The transmission electron micrographs of dislodged nanoparticles in aqueous solution showed the production
\end{abstract}


of reasonably monodisperse silver nanoparticles (average particle size: $4.66 \mathrm{~nm}$ ) by the fungus. The percentage of non hatching eggs treated with the Triclabendazole drug was $69.67 \%$, while this percentage increased to $89.67 \%$ in combination with drug and AgNPs.

Keywords: egg hatching; Fasciola; silver nanoparticle; Triclabendazole; Trichoderma

\section{Introduction}

Fasciola spesies is an important parasite of sheep and camel, so it has been the subject of many scientific investigations. This is not only because of its high prevalence rates but also due to its enormous production losses in these animals reported from various parts of the world. In addition, fasciolosis is now recognized as an emerging human disease by the World Health Organization. Fascioliasis, a serious infectious parasitic disease infecting domestic ruminants and humans, tops all the zoonotic helminthes worldwide [1]. It is caused by a liver fluke belonging to genus Fasciola. A large variety of animals, such as sheep, goats, cattle, buffalo, horses, donkeys, camels and rabbits, show infection rates that may reach $90 \%$ in some areas [2]. The infection with Fasciola spp. represents a major human health problem in diverse parts of Africa such as Egypt, Zambia, Kenya, Algeria, Zimbabwe, Tanzania and Nigeria [3-10], and recently, human infection cases with $F$. hepatica have been documented from southwest Tunisia, with prevalence infection of 6.6\% [11]. In Saudi Arabia, Fasciola gigantic counted as one of the most common gastrointestinal helminthes in camels in Saudi Arabia [12]. Fasciola sp. were with $14.5 \%$ prevalence from leafy vegetables in Riyadh region [13]. Fascioliasis among local and imported sheep in Saudi Arabia was studied [14]. This study showed that, the detection of eggs revealed $13.5 \%$ infection rate compared with $21.9 \%$ by detection of worms $(p<0.001)$. In addition, the infection rate was significantly higher $(p<0.001)$ among the imported sheep $(15.1 \%)$ than among the local ones $(4.96 \%)$. A report on stool analysis of male immigrant manual workers in Saudi Arabia, suggested that nine out of ten patients suffered from human fascioliasis [3,14,15]. Abou-Zinadah and Fouad [16] examined 20 imported sheep for fascioliasis natural infection by kato thick smear and by Fasciola-indirect haemagglutination test (IHAT). They reported that stool examination revealed infection in 13/20 (65\%), but IHAT identified 11/20 (55\%). Therefore, the sensitivity was $84.5 \%$.

At present, there is no vaccine available for the prevention of fascioliasis [17], and hence chemotherapy is the current mainstay of control. Triclabendazole is the drug of choice as it is safe and efficacious against both juvenile and adult flukes [18]. There is considerable concern of drug resistance development in humans, as drug resistance has already been reported from sheep and cattle from different parts of the world as e.g., Australia, Ireland, The Netherlands, Spain and the UK $[19,20]$. Currently, the interest in nanotechnological approaches in microbiology is growing rapidly, as in all fields of the science [21,22]. The main motive is the expectation that nanoparticles will be able to be used in the treatment of various diseases in the future [23-25]. In recent studies, it was determined that through their unique properties and large surface areas, metal oxide nanoparticles possess effective antimicrobial activities [25]. Particularly, owing to their great chemical reactivity, nanoparticles are capable of producing reactive oxygen species (ROS), which have the ability to kill infectious agents. 
The antibacterial and antiviral behaviors of silver, silver ions, and silver-containing compounds have long been investigated [26,27]. Ag-NPs demonstrated significant antileishmanial effects by inhibiting the proliferation and metabolic activity of promastigotes by 1.5 - to threefold, respectively, in the dark, and 2- to 6.5-fold, respectively, under UV light [28]. The preparation of uniform nanosized silver particles with specific requirements in terms of size, shape, and physical and chemical properties is of great interest in the formulation of new pharmaceutical products [29,30]. Currently, there is a growing need to using environmentally friendly nanoparticles that do not produce toxic wastes in their process synthesis protocol. To achieve this, we are inclined to shift to benign synthesis processes, which happen to be mostly of biological nature [31].

In the present investigation, we explore the potential of Trichoderma harzianum to synthesize AgNPs and test the drug efficacy of Triclabendazole alone and with AgNPs on egg hatching of Fasciola eggs.

\section{Results and Discussion}

HRTEM was employed to obtain direct information about the size of the produced Ag nanoparticles. Figure 1 shows the HRTEM image and the distribution size diagram of the Ag nanoparticles. The particles were separately dispersed on a on a carbon coated copper TEM grid and transmission electron microscopy (TEM) investigations were analyzed. TEM image of Ag nanoparticles revealed crystalline, free-standing, and approximately spherical particles as well as a number of aggregates. Average particle size calculated by log-normal fitting to the size distribution histogram, was obtained as $4.66 \mathrm{~nm}$. The silver nanoparticles are crystalline, as can be seen from the selected area diffraction pattern recorded from one of the nanoparticles in the aggregates (Figure 1 Inside). The separation between the silver nanoparticles seen in the TEM image could be due to capping by proteins and would explain the UV-Vis spectroscopy measurements, which is characteristic of well-dispersed silver nanoparticles. These monodispersed silver nanoparticles (biosynthesized by Trichoderma viride) showed emission in the range of 320-520 $\mathrm{nm}$ wavelength [32]. Considering the UV-vis intensity, wavelength, TEM and particle size distribution the most promising results obtained indicate that, the optimum conditions for preparation of silver nanoparticles colloids with excellent size and size distribution ranged from 3 to $8 \mathrm{~nm}$ could be produced using $10 \mathrm{~g}$ biomass of fungus $F$. solani; $0.085 \mathrm{~g} \mathrm{AgNO}_{3} ; \mathrm{pH} 12$; temperature, $\sim 25{ }^{\circ} \mathrm{C}$ and duration, $48 \mathrm{~h}$ [33]. The morphology of the nanoparticles synthesized by Trichoderma reesei was highly variable and these assemblies were found to be aggregates of silver nanoparticles in the size range 5-50 $\mathrm{nm}$ [34]. In addition, the nanoparticles were not in direct contact even within the aggregates, indicating stabilization of the nanoparticles by a capping agent [34]. AgNPs synthesized by different species of Trichoderma were found single or aggregated with round and uniform in shape and 6-80 nm in size [35]. Efficacy of AgNPs biosynthesis was reported due to reductase action or by electron shuttle quinones or both [36]. In fact, it is shown that the presence of hydrogenase and nitrate reductase are essential elements for metal reduction [36,37].

UV-visible absorption spectra for Ag NPs prepared from Trichoderma harzianum using silver nitrate are shown in Figure 2. The spectra recorded from the Ag NPs solution, it is seen that a blue shift in the onset of absorption is observed in this sample and showed an absorbance peak at $420 \mathrm{~nm}$, which was specific for the silver nanoparticles [38]. 
Figure 1. HRTEM image and size dispersion histogram of Ag nanoparticles.
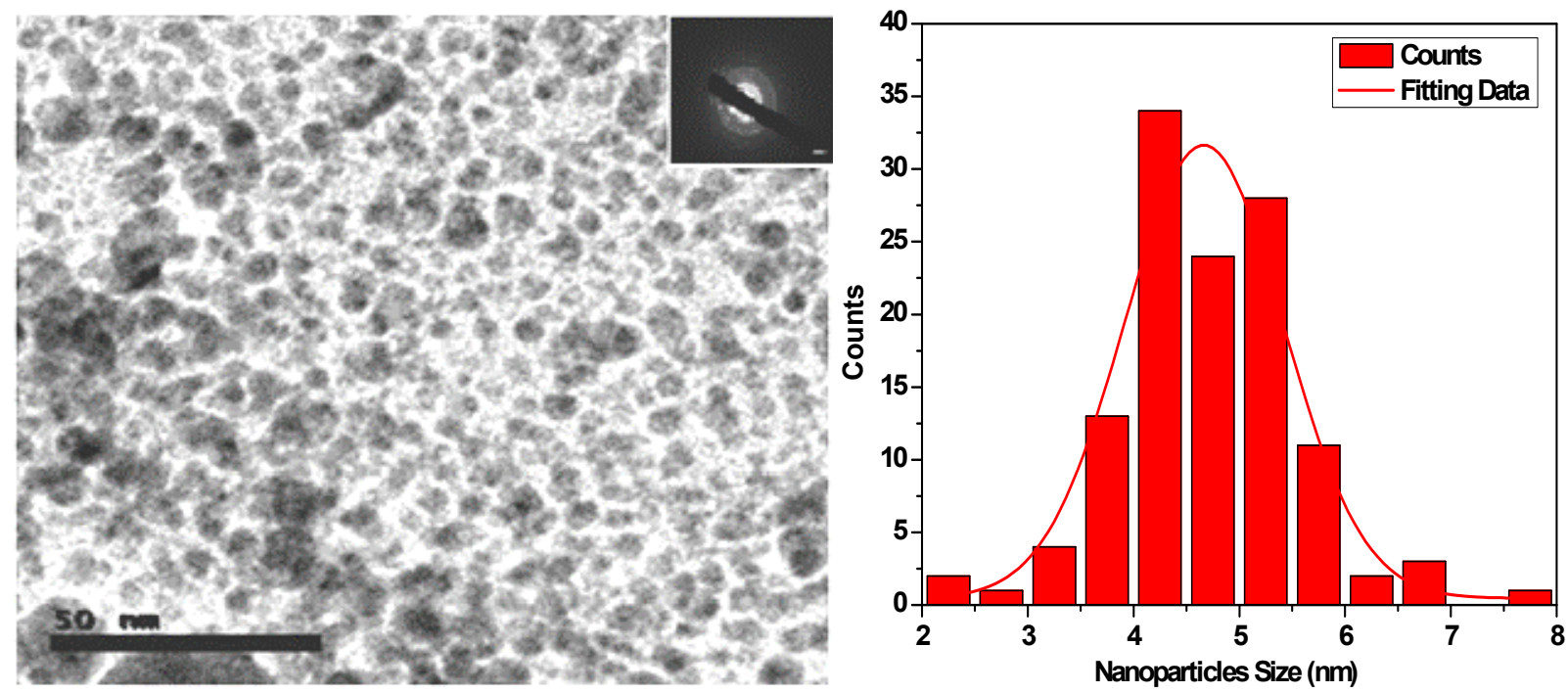

Figure 2. UV-visible spectra of fungal filtrate containing Ag nanoparticles.

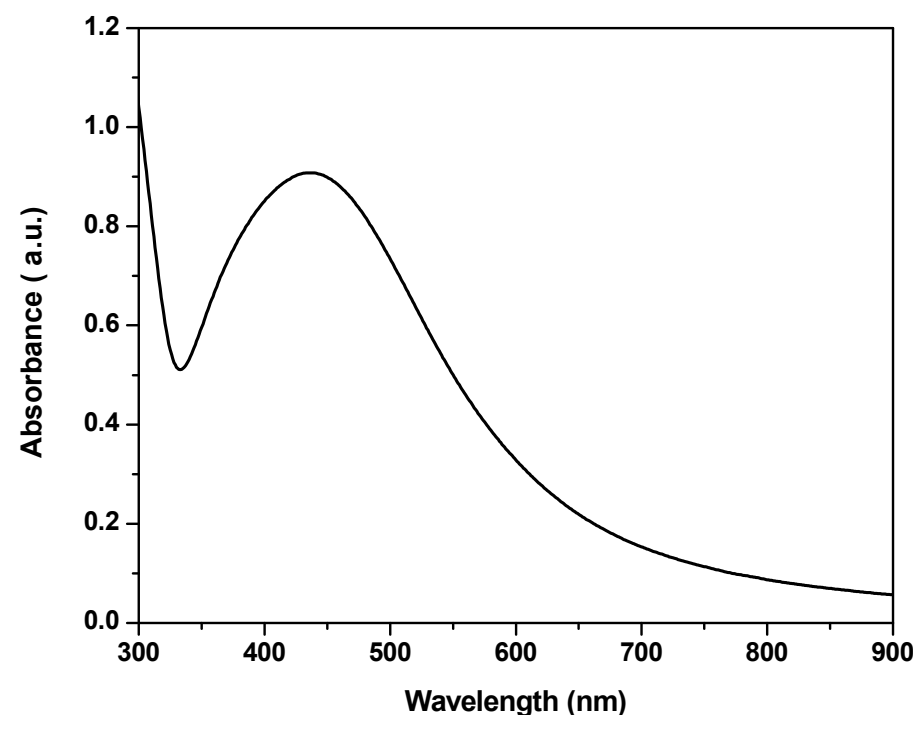

This phenomenon of blue shift of absorption edge has been ascribed to a decrease in particle size. This results in a shift in the absorption edge to a lower wavelength region. Furthermore, nanoparticles are highly sensitive and functionally efficient because of smaller grain size and high surface to volume ratio as compared to the conventional materials in micrometer range where in case of nano-scale materials most atoms, ions and defects would be on the surface.

It is observed, from the spectra of Trichoderma viride synthesized silver nano solution, that the silver surface plasmon band occurs at $405 \mathrm{~nm}$ in addition to prominent band at around $260 \mathrm{~nm}$ [32]. Aspergillus flavus when challenged with silver nitrate solution a characteristic surface Plasmon absorption band at $420 \mathrm{~nm}$ was observed at $24 \mathrm{~h}$ that attained the maximum intensity after $72 \mathrm{~h}$. After $72 \mathrm{~h}$ of incubation, no change in intensity at $420 \mathrm{~nm}$ was observed indicating complete reduction of silver ions [39]. The ultraviolet-visible spectra of Aspergillus terreus cell filtrate with $\mathrm{AgNO}_{3}$ showed a strong broad peak at $440 \mathrm{~nm}$ (SPR band), which indicated the presence of AgNPs [40]. Devi et al. [35] 
screened 75 isolates belonged to 5 Trichoderma species for Ag NBs. Their results indicated that the high Plasmon band was observed at $420 \mathrm{~nm}$ at every $24 \mathrm{~h}$.

Previously studies reported that the antimicrobial activities of AgNPs are size-dependent, the smallest sized showed the strongest effect [41]. Therefore, we already tested the smallest size of AgNPs (4.66 mm). Table 1 shows the results of Fasiola egg hatching experiment. The table shows that eggs were hatched at a percentage of $100 \%$ in non-treated control eggs. As for the in vitro treated eggs with the drug alone the ratio was $29.4 \%$ hatched and $70.6 \%$ non-hatched. As for that treated with the drug together with the silver nano particles (biologically synthesized from Trichoderma harzianum) the ratio was 9.4\% hatched and 90.6\% non-hatched. Applying ANOVA test on the hatched and non-hatched data with both treatments showed that $p<0.001$ (highly significant), with $F$ value 96.257.

Table 1. A comparison between hatched and non-hatched Fasciola eggs in both treatments (Drug alone) and (drug with AgNPs). As between both treatments the data is almost the same ( $p$ value is $<0.001$ ).

\begin{tabular}{|c|c|c|c|c|c|c|}
\hline \multirow{2}{*}{$\begin{array}{c}\text { Number of } \\
\text { eggs }\end{array}$} & \multicolumn{2}{|c|}{ Non-treated eggs } & \multicolumn{2}{|c|}{$\begin{array}{l}\text { Eggs in-vitro treated with } \\
\text { the drug alone }\end{array}$} & \multicolumn{2}{|c|}{$\begin{array}{l}\text { Eggs in-vitro treated with the drug } \\
\text { combined with nano particles }\end{array}$} \\
\hline & hatched & non-hatched & hatched & non-hatched & hatched & non-hatched \\
\hline 100 & 100 & 0 & 30 & 70 & 10 & 90 \\
\hline 100 & 100 & 0 & 25 & 75 & 5 & 95 \\
\hline 100 & 100 & 0 & 32 & 68 & 8 & 92 \\
\hline 100 & 100 & 0 & 28 & 72 & 11 & 89 \\
\hline 100 & 100 & 0 & 35 & 65 & 15 & 85 \\
\hline 100 & 100 & 0 & 32 & 68 & 13 & 87 \\
\hline Mean & 100 & 0 & 30.33 & 69.67 & 10.33 & 89.67 \\
\hline $\mathrm{SD}$ & 0 & 0 & 3.50 & 3.50 & 3.56 & 3.56 \\
\hline$F$ values & 0 & 0 & \multicolumn{2}{|c|}{96.26} & \multicolumn{2}{|c|}{96.26} \\
\hline Significance & 0 & 0 & \multicolumn{2}{|c|}{$<0.001$} & \multicolumn{2}{|c|}{$<0.001$} \\
\hline Percentage & $100 \%$ & $0 \%$ & $30.33 \%$ & $69.67 \%$ & $10.33 \%$ & $89.67 \%$ \\
\hline
\end{tabular}

Egg of Fasciola is oval measuring 120 micron long and 40 micron wide. It has an operculum on its top. The egg is immature when first laid by the worm. Under electron microscope, the egg surface texture is smooth with no ornamentations (Figure 3). Electron micrographs of eggs representing the three patches are showed in Figures 3-5. Figure 3 shows non-treated control egg, notice the smooth texture of the egg shell and the non-distorted eggs. Figure 4 shows the egg treated with the drug alone, notice the partly distorted surface and rough texture of the egg surface. Figure 5 shows the egg treated with the drug with the silver nano particles, notice the more distorted surface and the perforations that are obviously shown on the egg surface. 
Figure 3. Fasciola egg (control, non treated) Notice the smooth texture of the egg surface.

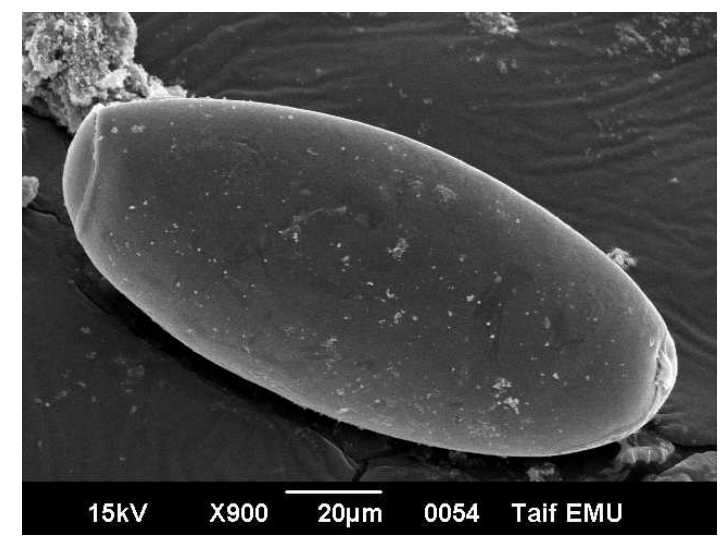

Figure 4. Fasciola egg treated in vitro with the drug only. Notice the alterations on the egg surface due to drug administration.

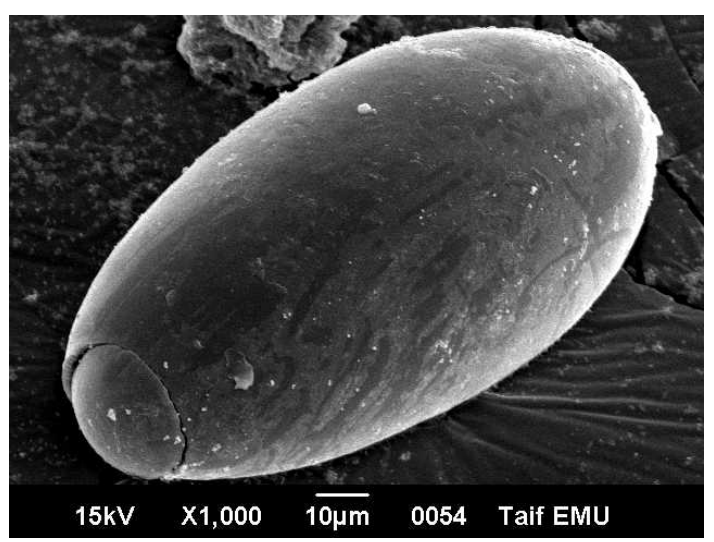

Figure 5. Fasciola egg treated in vitro with the drug with nano silver particles. Notice the perforations on the egg surface due to the effect of drug carried on nano silver particles.

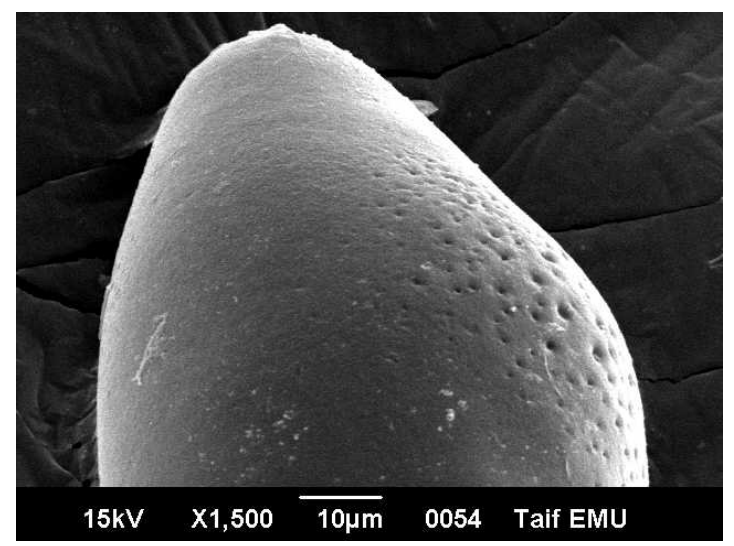

The results in Table 1 indicated that $30.33 \%$ of Fasciola eggs hatched in the presence of Triclabendazole sulfoxide (TCBZ). The results of Moll et al. [42] showed a significant reduction of $99.7 \%, 98.1 \%$ and $99.2 \%$, respectively, in fluke egg output at 21 days in all non-TCBZ treated animals. In addition, they reported that, TCBZ treatment produced percentage decreases of $15.3 \%$, $4.3 \%$ and $36.6 \%$, respectively. These results are highly indicative of the presence of TCBZ-resistant Fasciola hepatica in sheep and cattle on this farm. The efficacy of the drug has been reported to be 
minimized due to drug resistance in animals $[43,44]$. The results of the present work showed that the drug efficacy on the hatchability of Fasciola eggs is increases drastically using silver nano particles combined with the drug of choice $(10.33 \%$ and $30.33 \%$ respectively). Triclabendazole (TCBZ) is inhibiting of microtubule-dependent processes as a result of binding to the $\beta$-tubulin molecule [45-47]. However, if TCBZ action is associated with microtubule depolymerisation, some egg damage would be expected considering that the drug may accumulate within the egg in therapeutic concentrations [48]. Figure 5 showed the penetration sites of AgNPs to egg shill. This AgNPs may be cause membrane damage. The NPs that anchor onto Escherichia coli cell surface and penetrating the cells may cause membrane damage, which could result in cell lysis [49]. Ciprofloxacin-loaded nanoparticles were more active in human macrophages infected with Mycobacterium avium complex than free drug [50]. The efficacy of ampicillin was found to be increased by 120 -fold in murine salmonellosis by loading the drug into the nanoparticles [51]. The azithromycin nanoparticle preparations showed appropriate physicochemical and improved antimicrobial properties, which can be useful for oral administration [52]. Efficacy and broadening of antibacterial action of drugs enhanced via the use of capped Mesoporous nanoparticles [53]. In addition, surface plasmon enhanced drug efficacy using core-shell $\mathrm{Au} @ \mathrm{SiO}_{2}$ nanoparticle carrier as reported recently [54].

\section{Materials and Methods}

\subsection{Source of Microorganisms}

The fungus culture, Trichoderma harzianum (TUT89) was isolated from soil sample In Taif region and maintained in potato dextrose agar (HiMedia, Mumbai, India) slant at $27^{\circ} \mathrm{C}$. Internal transcribed spacer region (ITS) sequence for this strain was deposited in GenBank and its accession number is HE649481.

\subsection{Production of Biomass}

To prepare the biomass for biosynthesis studies the fungus was grown aerobically in liquid broth containing (g/L) $\mathrm{KH}_{2} \mathrm{PO}_{4}, 7 ; \mathrm{K}_{2} \mathrm{HPO}_{4}, 2 ; \mathrm{MgSO}_{4} \cdot 7 \mathrm{H}_{2} \mathrm{O}, 0.1 ;\left(\mathrm{NH}_{2}\right) \mathrm{SO}_{4}$, 1; yeast extract, 0.6; glucose, 10. The culture flasks were incubated on an orbital shaker at $27{ }^{\circ} \mathrm{C}$ and agitated at $150 \mathrm{rpm}$. The biomass was harvested after $72 \mathrm{~h}$ of growth by sieving through a plastic sieve followed by extensive washing with sterile double-distilled water to remove any medium components from the biomass [32].

\subsection{Synthesis of AgNPs}

Typically $20 \mathrm{~g}$ of biomass (wet weight) were brought into contact with $100 \mathrm{~mL}$ sterile double-distilled water for $48 \mathrm{~h}$ at $27^{\circ} \mathrm{C}$ in an Erlenmeyer flask and agitated as described above. After incubation, the cell filtrate was filtered by Whatman filter paper No.1 (Oakland, CA, USA). After filtration, the observed $\mathrm{pH}$ of cell filtrate was 7.2. Into these $100 \mathrm{~mL}$ of cell filtrate, a carefully weighed quantity of silver nitrate was added to the Erlenmeyer flask to yield overall Ag+ ions concentration of 10-3 M, and the reaction was carried out under dark conditions [32]. 


\subsection{Characterization of AgNPs}

\subsubsection{UV-Visible Spectral Analysis}

Change in color observed in the silver nitrate solution incubated with the tested strains. The UV-visible spectra of this solution recorded in spectrophotometer, from 200 to $800 \mathrm{~nm}$, at an interval of $24 \mathrm{~h}$. The silver nanoparticles dispersed in water by ultrasonication will be kept at room temperature $\left(37^{\circ} \mathrm{C}\right.$ ) for 3 months and the absorption peak at $420 \mathrm{~nm}$ will be measured continuously, to determine their stability.

\subsubsection{SEM, TEM and Electron Diffraction Analysis}

The freeze-dried mycelial mats (positive control and silver nitrate treated sample) mounted on specimen stubs with double-sided adhesive tape and coated with gold/palladium in a sputter coater and examined under SEM at $12-15 \mathrm{kV}$ with a tilt angle of $45^{\circ}$. For TEM, a drop of aqueous solution containing the silver nanomaterials placed on the carbon coated copper grids and dried under Infrared lamp.

\subsubsection{Effect of Triclabendazole and Ag NPs in F. hepatica}

Six-well multidishes were used for the experiments. One hundred eggs of $F$. hepatica isolate were placed into each well, as much water as possible drawn off, then $3 \mathrm{~mL}$ of a Triclabendazole sulfoxide (TCBZ.SO) solution (a drug of choice for Fascioliasis), specific concentration of AgNPs $(50 \mu \mathrm{g} / \mathrm{mL})$ and combination of Ag-NPs with TCBZ was added at a specific concentration $(0.1 \mu \mathrm{g} / \mathrm{mL})$; this was also true of the dimethyl sulfoxide (DMSO) solution in the control well. One replicate of each was set up in the same multidish, together with a separate control well containing DMSO at a concentration of $0.5 \%(v / v)$ in tap water. Previous experiments had shown that, at this concentration, the solvent did not affect egg development and hatching [55]. Separate multidishes were set up in the same way, to give a minimum of 3 replicates in total. The multidishes were placed into a dark incubator at $25^{\circ}$ and monitored every other day over a period of 14 days. At the end of the 14-day time period, the drug solution in each well was carefully removed and replaced with $3 \mathrm{~mL}$ of tap water. The plates were placed on a light box for $1-2 \mathrm{~h}$ to stimulate hatching, then each well was examined under a dissecting microscope and the number of eggs at each stage of development recorded using a tally chart [55].

\subsubsection{Data Processing and Statistics}

All experiments were repeated at least three times in triplicate wells. The results were expressed as the mean plus or minus the standard deviation. Data were analyzed using SPSS software (version 16.0 for Windows; SPSS Inc, Chicago, IL, USA) and $p<0.05$ values were considered statistically significant.

\section{Conclusions}

The present study indicates Ag-NPs has considerable antifasciolasis activity comparison with Triclabendazole drug, so deserving further investigation for clinical applications. 


\section{Acknowledgments}

This work was supported by a grant (Contract No. 2116-433-1) sponsored by Taif University, Saudi Arabia.

\section{Conflicts of Interest}

The authors declare no conflict of interest.

\section{References}

1. Haridy, F.M.; Morsy, T.A.; Gawish, N.I.; Antonios, T.N.; Abdel Gawad, A.G. The potential reservoir role of donkeys and horses in zoonotic fascioliasis in Gharbia Governorate. Egypt. J. Egypt. Soc. Parasitol. 2002, 32, 561-570.

2. Farag, H.F. Human fascioliasis in some countries of the Eastern Mediterranean Region. East. Mediterr. Health J. 1998, 4, 156-160.

3. Haseeb, A.N.; El-Shazly, A.M.; Arafa, M.A.; Morsy, A.T. A review on fascioliasis in Egypt. J. Egypt. Soc. Parasitol. 2002, 32, 317-354.

4. Lotfy, W.M.; El-Morshedy, H.N.; Abou El-Hoda, M.; El-Tawila, M.M.; Omarb, E.A.; Farag, H.F. Identification of the Egyptian species of Fasciola. Vet. Parasitol. 2002, 103, 323-332.

5. Mekroud, A.; Benakhla, A.; Vignoles, P.; Rondelaud, D.; Dreyfuss, G. Preliminary studies on the prevalences of natural fasciolosis in cattle, sheep, and the host snail (Galba truncatula) in north-eastern Algeria. Parasitol. Res. 2004, 92, 502-505.

6. Keyyu, J.D.; Kassuku, A.A.; Msalilwa, L.P.; Monrad, J.; Kyvsgaard, N.C. Cross-sectional prevalence of helminth infections in cattle on traditional, small-scale and large-scale dairy farms in Iringa district, Tanzania. Vet. Res. Commun. 2006, 30, 45-55.

7. Mungube, E.O.; Bauni, S.M.; Tenhagen, B.A.; Wamae, L.W.; Nginyi, J.M.; Mugambi, J.M. The prevalence and economic significance of Fasciola gigantica and Stilesia hepatica in slaughtered animals in the semi-arid coastal Kenya. Trop. Anim. Health Prod. 2006, 38, 475-483.

8. Pfukenyi, D.M.; Mukaratirwa, S.; Willingham, A.L.; Monrad, J. Epidemiological studies of Fasciola gigantica infections in cattle in the highveld and lowveld communal grazing areas of Zimbabwe. Onderstepoort J. Vet. Res. 2006, 73, 37-51.

9. Phiri, A.M.; Phiri, I.K.; Chota, A.; Monrad, J. Trematode infections in freshwater snails and cattle from the Kafue wetlands of Zambia during a period of highest cattle-water contact. J. Helminthol. 2007, 81, 85-92.

10. Ali, H.; Ai, L.; Song, H.Q.; Ali, S.; Lin, R.Q.; Seyni, B.; Issa, G.; Zhu, X.Q. Genetic characterisation of Fasciola samples from different host species and geographical localities revealed the existence of $F$. hepatica and F. gigantica in Niger. Parasitol. Res. 2008, 102, 1021-1024.

11. Hammami, H.; Hamed, N.; Ayadi, A. Epidemiological studies on Fasciola hepatica in Gafsa Oases (south west of Tunisia). Parasite 2007, 14, 261-264.

12. Banaja, A.A.; Ghandour, A.M. A review of parasites of camels in Saudi Arabia. J. KSU Sci. 1994, $6,75-86$. 
13. Al-Megrin, W. Prevalence of intestinal parasites in leafy vegetables in Riyadh, Saudi Arabia. Int. J. Zool. Res. 2010, 6, 190-195.

14. Sanad, M.M.; Al-Megrin, W.A. Fascioliasis among local and imported sheep in Saudi Arabia: Parasitological and serological diagnosis. J. Egypt. Soc. Parasitol. 2005, 35, 1121-1134.

15. Eligail, A.M.; Masawi, A.M.; Al-Jaser, N.M.; Abdelrahman, K.A.; Shah, A.H. Audit of stool analysis results to ensure the prevalence of common types of intestinal parasites in Riyadh region, Saudi Arabia. Saudi J. Biol. Sci. 2010, 17, 1-4.

16. Abou-Zinadah, N.Y.; Fouad, M.A. Anti-Fasciola antibodies among rodents and sheep in Jeddah, Saudi Arabia. J. Egypt. Soc. Parasitol. 2005, 35, 711-716.

17. McManus, D.P.; Dalton, J.P. Vaccines against the zoonotic trematodes Schistosoma japonicum, Fasciola hepatica and Fasciola gigantica. Parasitology 2006, 133, S43-S61.

18. Keiser, J.; Morson, G. Fasciola hepatica: Tegumental alterations in adult flukes following in vitro and in vivo administration of artesunate and artemether. Exp. Parasitol. 2008, 118, 228-237.

19. Alvarez-Sanchez, M.A.; Mainar-Jaime, R.C.; Perez-Garcia, J.; RojoVazquez, F.A. Resistance of Fasciola hepatica to triclabendazole and albendazole in sheep in Spain. Vet. Rec. 2006, 159, 424-425.

20. Keiser, J.; Engels, D.; Büscher, G.; Utzinger, J. Triclabendazole for the treatment of fascioliasis and paragonimiasis. Expert Opin. Investig. Drugs 2005, 14, 1513-1526.

21. Curtis, A.; Wilkinson, C. Nantotechniques and approaches in biotechnology. Trends Biotechnol. 2001, 19, 97-101.

22. Oka, H.; Tomioka, T.; Tomita, K.; Nishino, A.; Ueda, S. Inactivation of enveloped viruses by a silver-thiosulfate complex. Met. Based Drugs 1994, 1, doi:10.1155/MBD.1994.511.

23. Angeli, E.; Buzio, R.; Firpo, G. Nanotechnology applications in medicine. Tumori 2008, 94, 206-215.

24. Debbage, P. Targeted drugs and nanomedicine: Present and future. Curr. Pharm. Des. 2009, 15, 153-172.

25. Elechiguerra, J.L.; Burt, J.L.; Morones, J.R.; Camacho-Bragado, A.; Gao, X.; Lara, H.H.; Yacaman, M.J. Interaction of silver nanoparticles with HIV-1. J. Nanobiotechnol. 2005, 3, doi:10.1186/1477-3155-3-6.

26. Tokumaru, T.; Shimizu, Y.; Fox, C.L. Antiviral activities of silver sulfadiazine and ocular infection. Res. Commun. Chem. Pathol. Pharmacol. 1974, 8, 151-158.

27. Oloffs, A.; Grosse-Siestrup, C.; Bisson, S.; Rinck, M.; Rudolph, R.; Gross, U. Biocompatibility of silver-coated polyurethane catheters and silver-coated Dacron material. Biomaterials 1994, 15, 753-758.

28. Allahverdiyev, A.M.; Abamor, E.S.; Bagirova, M.; Ustundag, C.B.; Kaya, C.; Kaya, F.; Rafailovich, M. Antileishmanial effect of silver nanoparticles and their enhanced antiparasitic activity under ultraviolet light. Int. J. Nanomed. 2011, 6, 2705-2714.

29. Brigger, I.; Dubernet, C.; Couvreur, P. Nanoparticles in cancer therapy and diagnosis. Adv. Drug Deliv. Rev. 2002, 54, 631-651.

30. Merisko-Liversidge, E.; Liversidge, G.G.; Cooper, E.R. Nanosizing: A formulation approach for poorly-watersoluble compounds. Eur. J. Pharm. Sci. 2003, 18, 113-120.

31. Mansoori, G.A. Principles of Nanotechnology-Molecular-Based Study of Condensed Matter in Small Systems; World Scientific Pub. Co.: Hackensack, NJ, USA, 2005. 
32. Fayaza, M.; Tiwaryb, C.S.; Kalaichelvana, P.T.; Venkatesanc, R. Blue orange light emission from biogenic synthesized silver nanoparticles using Trichoderma viride. Colloids Surf. B 2010, 75, 175-178.

33. El-Rafie, M.H.; Mohamed, A.A.; Shaheen, T.A.; Hebeish, A. Antimicrobial effect of silver nanoparticles produced by fungal process on cotton fabrics. Carbohydr. Polym. 2010, 80, 779-782.

34. Vahabi, K.; Mansoori, G.A.; Karimi, S. Biosynthesis of silver nanoparticles by fungus Trichoderma reesei (A route for large-scale production of AgNPs). Insci. J. 2011, 1, 65-79.

35. Devi, T.P.; Kulanthaivel, S.; Kamil, D.; Borah, J.L.; Prabhakaran, N.; Srinivasa, N. Biosynthesis of silver nanoparticles from Trichoderma species. Indian J. Exp. Biol. 2013, 51, 543-547.

36. Duran, N.; Marcato, P.; Alves, O.; de Souza, G.; Esposito, E. Mechanistic aspects of biosynthesis of silver nanoparticles by several Fusarium oxysporum strains. J. Nanobiotechnol. 2005, 3, 1-7.

37. Ottow, J.C.G.; von Klopotek, A. Enzymatic reduction of iron oxide by fungi. Appl. Microbiol. 1969, 18, 41-43.

38. Mulvaney, P. Surface plasmon spectroscopy of nanosized metal particles. Langmuir 1996, 12, 788-800.

39. Vigneshwaran, N.; Kathe, A.A.; Varadarajan, P.V.; Nachane, R.P.; Balasubramanya, R.H. Silver-protein (core-shell) nanoparticle production using spent mushroom substrate. Langmuir 2007, 23, 7113-7117.

40. Li, G.; He, D.; Qian, Y.; Guan, B.; Gao, S.; Cui, Y.; Yokoyama, K.; Wang, L. Fungus-mediated green synthesis of silver nanoparticles using Aspergillus terreus. Int. J. Mol. Sci. 2012, 13, 466-476.

41. Lu, Z.; Rong, K.; Li, J.; Yang, H.; Chen, R. Size-dependent antibacterial activities of silver nanoparticles against oral anaerobic pathogenic bacteria. J. Mater. Sci. Mater. Med. 2013, 24, 1465-1471.

42. Moll, L.; Gaasenbeek, C.P.; Vellema, P.; Borgsteede, F.H. Resistance of Fasciola hepatica against triclabendazole in cattle and sheep in The Netherlands. Vet. Parasitol. 2000, 91, 153-158.

43. Raadsma, H.W.; Kingsford, N.M.; Suharyanta, T.W.; Spithill, D.P. Host responses during experimental infection with Fasciola gigantic and Fasciola hepatica in Merino sheep I. Comparative immunological and plasma biochemical changes during early infection. Vet. Parasitol. 2007, 143, 275-286.

44. Ramírez, N.; Mayet, L.; del Rivero, L.; Ibarra-Velarde, F.; Castillo, R.; Hernández-Campos, A.; Jung-Cook, H. Pharmacokinetic behaviour in sheep and cattle of 5-Chloro-2-(methylthio)-6-(1naphthyloxy)-1H-benzimidazole, a new fasciolicide agent. J. Vet. Pharmacol. Ther. 2009, 32, 154-159.

45. Lacey, E. Mode of action of benzimidazoles. Parasitol. Today 1990, 6, 112-115.

46. Fairweather, I. Triclabendazole: New skills to unravel an old(ish) enigma. J. Helminthol. 2005, 79, 227-234.

47. Fairweather, I. Triclabendazole progress report 2005-2009: An advancement of learning? J. Helminthol. 2009, 83, 139-150.

48. Alvarez, L.; Moreno, G.; Moreno, L.; Ceballos, L.; Shaw, L.; Fairweather, I.; Lanusse, C. Comparative assessment of albendazole and triclabendazole ovicidal activity on Fasciola hepatica eggs. Vet. Parasitol. 2009, 164, 211-216. 
49. Ansari, M.A.; Khan, H.M.; Khan, A.A.; Ahmad, M.K.; Mahdi, A.A.; Pal, R.; Cameotra, S.S. Interaction of silver nanoparticles with Escherichia coli and their cell envelope biomolecules. J. Basic Microbiol. 2013, doi:10.1002/jobm.201300457.

50. Fawaz, F.; Bonini, F.; Maugein, J.; Lagueny, A.M. Ciprofloxacin-loaded polyisobutylcyanoacrylate nanoparticles: Pharmacokinetics and in vitro antimicrobial activity. Int. J. Pharm. 1998, 168, 255-259.

51. Fattal, E.; Rojas, J.; Youssef, M.; Couvreur, P.; Andremont, A. Liposome-entrapped ampicillin in the treatment of experimental murine listeriosis and salmonellosis. Antimicrob. Agents Chemother. 1991, 35, 770-772.

52. Mohammadi, G.; Valizadeh, H.; Barzegar-Jalali, M.; Lotfipour, F.; Adibkia, K.; Milani, M.; Azhdarzadeh, M.; Kiafar, F.; Nokhodchi, A. Development of azithromycin-PLGA nanoparticles: Physicochemical characterization and antibacterial effect against Salmonella typhi. Colloids Surf. B Biointerfaces 2010, 80, 34-39.

53. Mas, N.; Galiana, I.; Mondragon, L.; Aznar, E.; Climent, E.; Cabedo, N.; Sancenón, F.; Murguía, J.R.; Martínez-Máñez, R.; Marcos, M.D.; Amorós, P. Enhanced efficacy and broadening of antibacterial action of drugs via the use of capped mesoporous nanoparticles. Chem. A Eur. J. 2013, 34, 11167-11171.

54. Chu, Z.; Yin, C.; Zhang, S.; Lin, G.; Li, Q. Surface plasmon enhanced drug efficacy using core-shell Au@SiO2 nanoparticle carrier. Nanoscale 2013, 5, 3406-3411.

55. Fairweather, I.; McShane, D.D.; Trudgett, A.; Brenna, G.P.; Shaw, L.; Ellison, S.E.; O’Hagan, N.T.; York, E.A.; Trudgett, A.; Brennan, G.P. Development of an egg hatch assay for the diagnosis of triclabendazole resistance in Fasciola hepatica: Proof of concept. Vet. Parasitol. 2012, 183, 249-259.

(C) 2013 by the authors; licensee MDPI, Basel, Switzerland. This article is an open access article distributed under the terms and conditions of the Creative Commons Attribution license (http://creativecommons.org/licenses/by/3.0/). 